\title{
Partial Trisomy 15q and Partial Monosomy 17q in a Boy with Various Dysmorphic Findings
}

\author{
Büşra Eser Çavdartepe $\mathbb{B}^{1}{ }^{1,}$, Nadir Koçak ${ }^{1}$ and Tülin Çora ${ }^{1}$ \\ ${ }^{1}$ Department of Medical Genetics, Faculty of Medicine, Selcuk University, Faculty of Medicine, Konya, Turkey \\ "Corresponding author: Department of Medical Genetics, Faculty of Medicine, Selcuk University, Alaeddin Keykubat Campus, 42130, Selcuklu, Konya, Turkey. Tel: \\ +90-3322243934, Email: bsraesr@gmail.com \\ Received 2018 April 16; Accepted 2019 January 08.
}

\section{Dear Editor,}

Trisomies are the most common chromosomal anomalies in humans and constitute about $4 \%$ of clinically prescribed pregnancies (1). Trisomy 15, from these, is incompatible with life and constitutes $1.7 \%$ of spontaneous abortions (1). Partial trisomies display milder clinical signs than complete trisomies. The partial trisomy of the 15th chromosome has been reported for the first time in 1974, which is life-compatible and is a rare chromosomal anomaly (2). This chromosomal rearrangement often occurs as an unbalanced segregation product of a parent with balanced translocation. The fracture regions in the majority of the cases are $15 q 22$ and distal to it $(3,4)$. The chromosomal rearrangement that causes partial trisomy 15 , the other chromosome that accompanies chromosome 15, varies between cases. In this report, we present a case of partial trisomy 15, which appears as an unbalanced segregation product of a mother with a reciprocal translocation between chromosomes 15 and 17.

A 5-month-old male infant was directed to our clinic because of atypical facial appearance. The patient was the first child of the family and his parents were 25 years old. Parents were first-degree cousins. Physical examination of the patient revealed microcephaly, low-set ears, high palate, micrognathia, triangular facial structure, bilateral ptosis, short philtrum, prominent nasal structure, full cheeks, widely spaced nipples, pectus excavatum, arachnodactyly and elongated foot structure (Figure 1). There was also anal stenosis, right sided inguinal hernia and undescended testis in the patient. Hypertonicity was observed in the patient. Echocardiography revealed mild pulmonary stenosis and patent foramen ovale. When the family story was questioned, it was learned that the child of the patient's aunt (III-5) had a developmental retardation and patient's uncle (II-5) could not have children from his two marriages (Figure 2). After obtaining written informed consent, cytogenetic analyses were performed from the patient and his parents.

As a result of conventional cytogenetic analysis of the patient, the karyotype was 46,XY,der(17)t(15;17)(q22;q25). In the parents, karyotype 46,XX,t(15;17)(q22;q25) was detected in the mother and $46, \mathrm{XY}$ in the father. According to these results, our proband had inherited an unbalanced segregation product in the 2:2 meiotic segregation of the translocation carrier mother. Our patient is partial trisomic for chromosome 15 and partial monosomic for chromosome 17(Figure 3). The phenotypic features present in the patient are partially compatible with the reported partial trisomy 15 cases, but also contain some differences. The reason for these differences may be related to the partial monosomy of the 17th chromosome, the second chromosome associated with translocation (5). A case reported in 2000 has the same karyotype as our proband and is similar in clinical findings (6). Low-set ears, prominent nasal structure, high palate, micrognathia, short neck and cardiac findings are common, while arachnodactyly, pectus excavatum, hypertonicity, inguinal hernia and undescended testis are different findings present in our case. In conclusion, it is important to take family history and make appropriate diagnostic tests in a child with multiple congenital anomalies, so that detailed genetic counseling can be given to the family.

\section{Footnotes}

Authors' Contribution: Article writing and information gathering: Büşra Eser Çavdartepe; patient examination: Nadir Koçak and Büşra Eser Çavdartepe; genetic analysis: Tülin Çora, Nadir Koçak, and Büşra Eser Çavdartepe.

Conflict of Interests: Authors mention that there is no conflict of interest in this study.

Funding/Support: It is not declared by the authors.

Copyright (c) 2019, Author(s). This is an open-access article distributed under the terms of the Creative Commons Attribution-NonCommercial 4.0 International License (http://creativecommons.org/licenses/by-nc/4.0/) which permits copy and redistribute the material just in noncommercial usages, provided the original work is properly cited. 

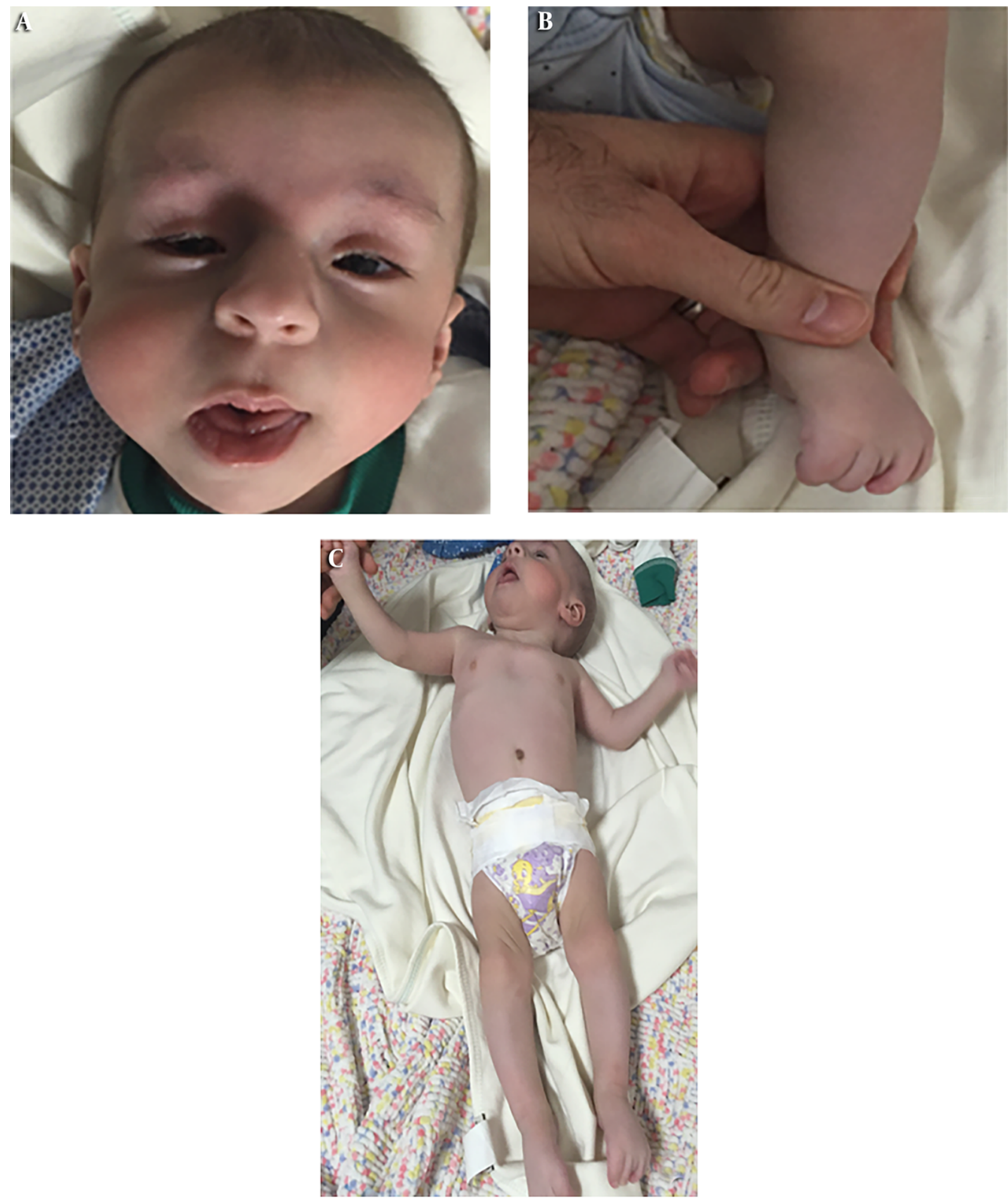

Figure 1. Phenotypic characteristics of proband. A, Microcephaly, low set ears, micrognathia, triangular facial structure, bilateral ptosis, prominent nasal structure, full cheeks; B, elongated foot structure; and C, hypertonicity, widely spaced nipples, pectus excavatum, arachnodactyly. 


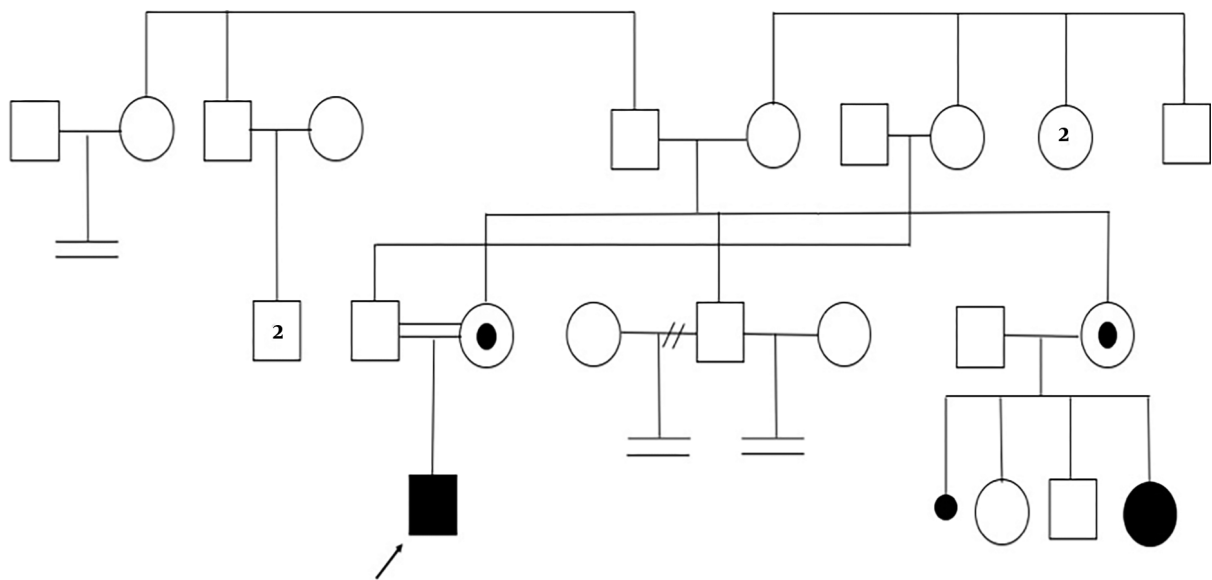

Figure 2. Pedigree of the family

Mother


15

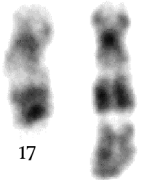

$\operatorname{der}(17)$
Proband

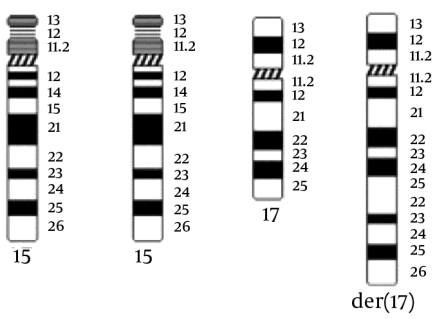

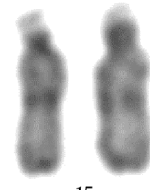

15



$\operatorname{der}(17)$

Figure 3. Rearranged chromosomes of the mother and proband

\section{References}

1. Hassold TJ, Jacobs PA. Trisomy in man. Annu Rev Genet. 1984;18:69-97. doi:10.1146/annurev.ge.18.120184.000441. [PubMed: 6241455].

2. Fujimoto A, Towner JW, Ebbin AJ, Kahlstrom EJ, Wilson MG. Inherited partial duplication of chromosome No.15.JMed Gen.1974;11(3):287-91. doi: 10.1136/jmg.11.3.287.

3. Scarbrough PR, Finley W, Finley S. Complex chromosome rearrangement resulting in trisomy-15q22-qter. Am J Hum Gen.1981;33(6). A119.

4. Schnatterly P, Bono KL, Robinow M, Wyandt HE, Kardon N, Kelly TE. Distal 15q trisomy: phenotypic comparison of nine cases in an ex- tended family. Am J Hum Genet. 1984;36(2):444-51. [PubMed: 6711563]. [PubMed Central: PMC1684424].

5. Puvabanditsin S, Khan I, Garrow E, Botti C, Lambert G, Quan M. Partial trisomy $15 q 23$ and partial monosomy 5p15.32: Case report and a literature review. Am J Med Genet A. 2013;161A(12):3201-4. doi: 10.1002/ajmg.a.36150. [PubMed: 24038903].

6. Cora T, Acar H, Oran B. A partial trisomy 15q due to 15;17 translocation detected by conventional cytogenetic and FISH techniques. Genet Couns. 2000;11(1):25-32. [PubMed:10756424]. 